\title{
Contribuição ao estudo dendrológico de 5 Parkias (Leguminosae) da Amazônia
}

\author{
ARTHUR A. LOUREIRO(*) \\ MARLENE Freitas DA Sulva(*) \\ Instituto Nacional de Pesquisas \\ da Amazònia
}

\begin{abstract}
SINOPSE
Estudadas 5 espécies euxilóforas da Amazônia, pertencentes ao gênero Parkia (Leguminosae): P. pendula, P. decussata, P. oppositifolia, P. gigantocarpa e P. multijuga. Para cada espécie são apresentados os seguintes dados : a) da árvore - descrição botânica, habitat, ocorrência geográfica e nomes vulgares; b) da madeira - caracteres gerais, descriçāo macro e microscópica e usos comuns. Ilustram o trabalho 5 macros e 10 microfotografias do lenho das espécies referidas.
\end{abstract}

\section{INTRODUÇĀo}

O gênero seg. Ducke (1949), abrange cerca de 30 espécies tropicais, das quais, todas as ocorrentes na América, são representadas na Hiléia, onde se destacam não só na composição florística da mata pela beleza e porte de seus indivíduos, como, por representarem papel importante no setor econômico regịonal, produzindo madeiras leves e pesadas de coloração clara e de aplicação variável.

Dentre as espécies que habitam as matas amazônicas, algumas merecem atenção especial por serem tipicamente ornamentais como a inconfundivel $P$. pendula, há muito recomen. dada para arborização de praças $\in$ logradouros públicos. Conforme material de herbário consultado, constatamos a ocorrência da $P$. decussata nas áreas próximas de Manaus, embora com pouca freqüência, e da $P$. gigantocarpa no Território Federal do Amapá (Serra áo Navio), aumentando deste modo as suas áreas de dis. tribuição geográfica.

A aplicação da madeira destes indivíduos, seg. Ducke (1949) era desconhecida. Porém, Tavares (1959), ressalta a utilização do lenho da $P$. pendula, para táboas, caixotarias, etc., e o aproveitamento do tronco para a fabricação de botes ou canoas. Mainieri (1962), recomenda o emprego das madeiras de $P$. opposititolia e $P$. multijuga na fabricaçăo "em larga escala de caixas para embalagem".

\section{MATERIAL}

O material que pesquisamos, encontra-se registrado e arquivado no Herbário e Xiloteca do INPA, IAN e MG, com os seguintes dados de coletas :

\section{1 - Parkia pendula}

Herb. INPA 21.335

Proc. Brasil, Amaz., estr. Manaus - Itacuatiara, km 190, picada 26, A-46.

Leg. W. Rodrigues et al., 8505, em 3/VII/968 (fl. jovens)

Herb. INPA 23.186; X-3729.

Proc. Est. Acre, estr. Abună-Rio Branco.

Leg. G. Prance et al., 6428, em 22/VII/968 (fr. jovem)

Herb. INPA 15.647; X- 3729.

Proc. Brasil, Amaz., Manaus, Reserva Florestal Ducke, Q.6, A-641 Fenológico.

Leg. W. Rodrigues \& O. Pires, 6985, em 28/VII/965 (fl.); (fr.) em 26/V/966.

Herb. INPA 11.816

Proc. Brasil, Pará, rodovia Belém-Brasília, km 94

Leg. J. Kuhlmann \& S. Jimbo, 256 em 16/IX/965 (fr. jovem) INPA, X - 2775.

Proc. Brasil, Amaz., Reserva Florestal Ducke

(*) - Bolsista do Conselho Nacional de Pesquisas. 
Leg. A. Loureiro, L. Coelho \& F. Mello, 19/V/964

INPA, X- 4759

Proc. Brasil, Amaz., estr. Manaus - Itacoatiara, km 145

Leg. A. Loureiro, D. Coelho \& O. Pires

\section{2 - Parkia decussata}

Herb. INPA 21.248; X-3915

Proc. Brasil, Amaz., estr. Manaus - Itacoatiara, km 104

Leg. L. Coelho et al., s/n, em 27/V/968 (fr.)

\section{3 - Parkia oppositifolia}

Herb. INPA 6481; X - 1074

Proc. Brasil, Amaz., Município de Codajás, estr. do Cemitério

Leg. E. Ferreira, s/n., em 23/IV/958

Herb. INPA $16.967 ; X-3466$

Proc. Brasil, Amaz., Manaus, estr. Manaus - Itacoatiara, $\mathrm{km} \mathrm{135}$, picada XV.

Leg. W. Rodrigues, 7662 , em 2/X/965

Herb. INPA 17.141

Proc. Brasil, Amaz., Manaus, Reserva Flo. restal Ducke, Fenológico 203

Leg. W. Rodrigues \& D. Coeiho, 7838 , em 18/V/966.

Herb. INPA 15.519; X - 2967

Proc. Brasil, Amaz.r Manaus, Reserva Florestal Ducke, picada D

Leg. W. Rodrigues \& A. Loureiro, 5807 em $29 /$ IV $/ 964$

INPA X - 1067

Proc. Brasil, Amaz., cachoeira Alta do Tarumã.

Leg. J. Lima \& D. Coelho, em 4/VII/61

Herb. INPA 1074

Proc. Brasil, Amaz., Manaus, cachoeira do Tarumä

Leg. J. Chagas, $s / n$.

Herb. INPA 14.169

Proc. Brasil, Amaz., Manaus, Reserva Flo. restal Ducke, Q. 33,A-4382

Leg. W. Rodrigues, 5496, em 11/X/963

INPA X - 3184, (IAN 105.217)

Proc. Brasil, Pará, Belém

Leg. Oliveira, 477

\section{4 - Parkia gigantocarpa}

Herb. INPA 10.287 ; X - 1278

Proc. Brasil, Ter. Fed. Amapá, serra do Navio

Leg. W. Rodrigues, 2932, em 1961 (estéril)

\section{5 - Parkia multijuga}

Herb. INPA 14.426

Proc. Brasil, Amaz., Reserva Florestal Ducke, Q. 2, A-226

Leg. W. Rodrigues \& O. Pires, 5714, em 10/il/964 (fl.)

Herb. INPA $21.125, X-3892$

Proc. Brasii, Amaz., Manaus, Reserva Florestal Ducke

Le g. W. Rodrigues et al. 8476, em 26/ill/968 (tr. passados)

Herb. INPA 21.194

Proc. Brasil, Amaz., estrada Manaus - Itacoatiara, km 85

Leg. W. Rodrigues, 8483 , em 24/IV/968 (fr. jovem)

Herb. INPA 15.041; X - 2954

Proc. Brasil, Amaz., Manaus, Reserva Florestal Ducke, bosque ao lado da Estação de Metereologia.

Leg. W. Rodrigues \& O. Pires, 5992, em 6/VIII/964 (fr.)

Herb. INPA 15.770; X - 3221

Proc. Brasil, Amaz., Manaus Estr. Manaus - Itacoatiara, $\mathrm{km} 84$

Leg. W. Rodrigues \& A. Loureiro, 7108, em $2 / I X / 965$ (fr. jovem)

INPA $X \cdot 1150$

Proc. Brasil, Pará, Santarém, Curuá-Una.

\section{MÉToDo}

Para a descrição botânica das espécies, utilizamos material herborizado seguramente identificado, confrontando os seus caracteres morfológicos com a descrição original dos autores das espécies estudadas, acrescentadas algumas particularidades que muito podem au. xiliar na identificação das referidas espécies. A distribuição geográfica, o habitat e os diversos nomes vulgares adotados nos diferentes lo. cais, foram concluidos dos diversos trabalhos consultados e material de herbário. 
Para as lâminas, foi tirado tanto do cerne como do alburno um corpo de prova cúbico, de cerca de $1 \mathrm{~cm}$ de aresta, de cada amostra. Todo o material foi submetido a ebulição em água durante 30 minutos. Em seguida, feitos alguns cortes transversalmente ao eixo da árvore, e outros no sentido longitudinal: perpendicularmente aos raios (tangencial) e paralelamente a estes (radial), em micrótomo Jung $R$. jungag, empregando sempre a técnica comum, dividindo os cortes em três grupos: uns permanecem na cor naturai, outros são coloridos pela safranina hidroalcoólica, e o restante pela hematoxilina de Delafield e finalmente montados em bálsamo do canadá entre lâmina e laminuia.

A terminologia usada para a descriçâo anatômica, segue Milanez e Bastos (1960), e a avaliação das grandezas obedece as normas de Chattaway (1932).

Para maceração, tiramos pequenas las-cas da parte mais interna do corpo de prova, mergulhando-as em solução aquosa de ácido nítrico a $40 \%$. Para apressar a ação do ácido. aquecemo-lo em um tubo de ensaio durante 20 minutos. No dia seguinte o material foi lavado várias vezes em água corrente e corado em safranina hidroalcoólica. Após a coloração e nova lavagem, foi dissociado sobre lâmina em uma gota de glicerina com auxílio de agulhas histológicas e lupa Olympus. Em seguida procedemos a montagem das lâminas para as devidas medições.

Parkia pendula Benth. in Mart. FI. Bras. XV (III) : 265.

=Inga pendula Willd; Mimosa pendula Poir.

BRASIL : Est. Amazonas - Arara tucupi, Visgueiro (Manaus). Est. Pará - Visgueiro (Belém, Bragança); Boloterio, Rabo de Arara, Jupuuba (rio Trombetas), Seg. Ducke (1949); Fava bolota (Curuá-Una). Est. Maranhão - Faveira de chorão. Tavares (1959). Est. Bahia - Visgueiro, joerana, Jeeirana, Arara petiu, Fava de bolota, Faveira de berloque, Faveirão, Joarana, Juerana, Jupiuba, Jupuuba, Macaqueiro, Mafua, Muirarema, Muirareina, Paricá, Pau de arara, Procaxi, Sabiu, Pau de sândalo. Mene. zes (1949). Est. Pernambuco - Visgueiro. Tavares (1959), Braga (1960).

SURINAME: Kwatakama, Ipana. Lindeman \& Mennega (1963).

GUIANA FRANCESA: Male bois macaque Acacia mâle (Créole); Kouatakaman (Pamaka e Saramaka); Ipanai, Hipanai (Demerara). Bena (1960). Grignon fou. Le Cointe (1947).

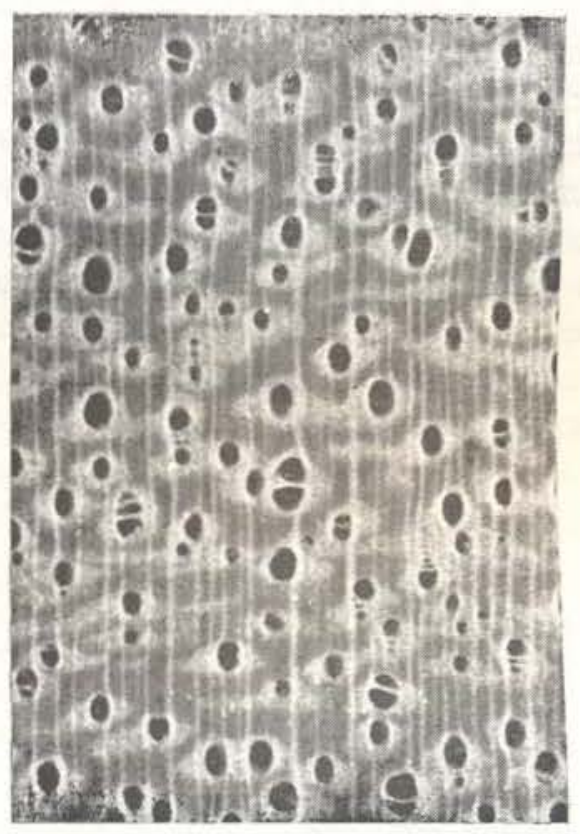

Secção transversal (10X)

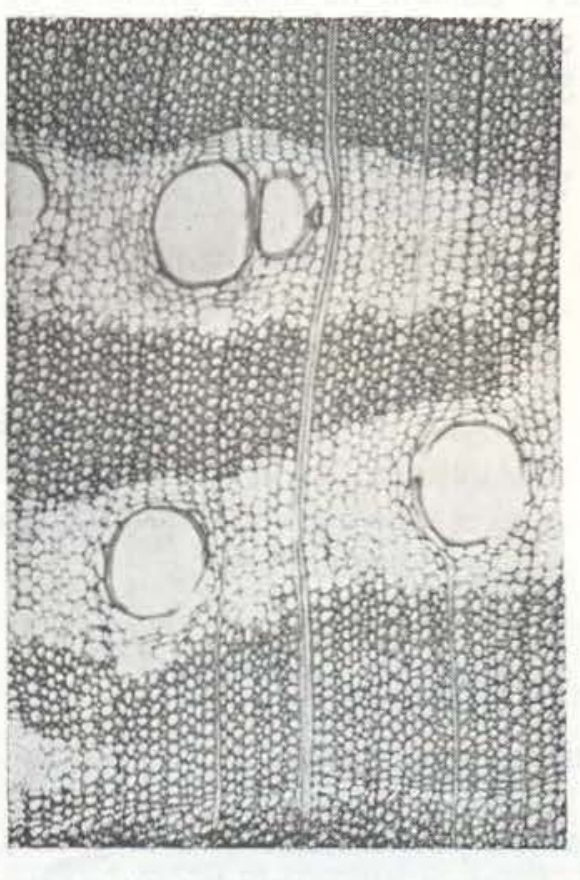

Secção transversal (60X) 
Árvore de significativo porte, ornamental, inconfundível mesmo à distância, pelo aspecto tabular de sua copa, sob a qual permanecem pendentes por algum tempo as inflorescências ou os frutos. Fuste cilindrico, ereto, ocasionalmente com pequena sapopema na base, emitindo no ápice grossos e longos galhos mais ou menos horizontais, recobertos por uma folhagem fina, densa e verde escura. Folhas alternas, compostas, biparipenadas; pecíolo 15 (20) $\mathrm{cm}$ de comprimento, ráquis delgado, sustentando 20 (22) pares de pinas multifolioluladas, opostas a subopostas, com numerosos foliólulos lineares, ligeiramente curvados nas extremidades. Flo. res em inflorescências capitulares, estericas, vermelho-escuras, tetidas em plena antese, pendendo de longos e filiformes pedúnculos, que vao de $1 \mathrm{~m}$ a mais de comprimento. Frutos legumes planos, talcitormes, deiscentes, longoestıpıtados, reunidos no ápice espessado do pedúnculo, exudando quando maduros uma resina viscosa. Sementes arredondadas, comprimidas, unisseriadas no fruto.

Obs. O odor que exalam as flores, e, a resina que exudam os frutos, constituem o úni co inconveniente na introdução desta espécie para ornamentação de parques e jardins públicos.

Habitat: Comum na mata primaria ou secun. dária da terra firme, em solo argiloso. Seg. Fróes (1959), é ainda muito comum "nas margens dos rios de barrancos, da terra firme".

Outras aplicaçōes: Le Cointe (1947), atribui ação anti-hemorrágica ao cozimento concentrado das cascas.

Ocorrência geográfica: Comum nos Estados do Amazonas e Pará, e observada ainda nos Estados de Pernambuco, Bahia, Alagoas e Guianas.

DADOS GERAIS SOBRE A MADEIRA

$\Rightarrow$

CARACTERÍSTICAS GERAIS :

Madeira pesada $\left(0,80-0,85 \mathrm{~g} / \mathrm{cm}^{3}\right)$; cerne e alburno pouco diferenciados ou mesmo indis- tintos; quando verde o cerne apresenta-se levemente avermelhado, passando com o tempo para pardo amarelado brilhante ou creme; insípida e inodora; textura de média para grosseira; grā obliqua e sinuosa. Fácil de trabalhar, podendo receber polimento um tanto atrativo. É uma madeira predisposta ao ataque de fungos $e$ insetos.

DESCRIÇĀO MACROSCÓPICA :

Parênquima relativamente abundante, distinto a olho nu, predominantemente aliforme, ora apresentando aletas curtas, ora mais longas ligando e envolvendo os poros, ás vezes com pequena tendencia para contiuente, sımultaneamente vasicentrico. Poros bem distintos sem auxílio de lente, pequenos e grandes; pouco numerosos, solitários predominantes, múltipios de $2-3$ poros, rarissimos de 4 , vazios. Linhas vasculares visíveis a simples vista, altas, retas. Raios no topo apenas notados a olho nu, relaiivamente abundantes, apresentando boa uniformidade na largura e espaçamento; na superficie tangencial são irregularmente dispostos, baixos e de tamanho homogêneo; no corte radial são contrastados notados mesmo sem aju-

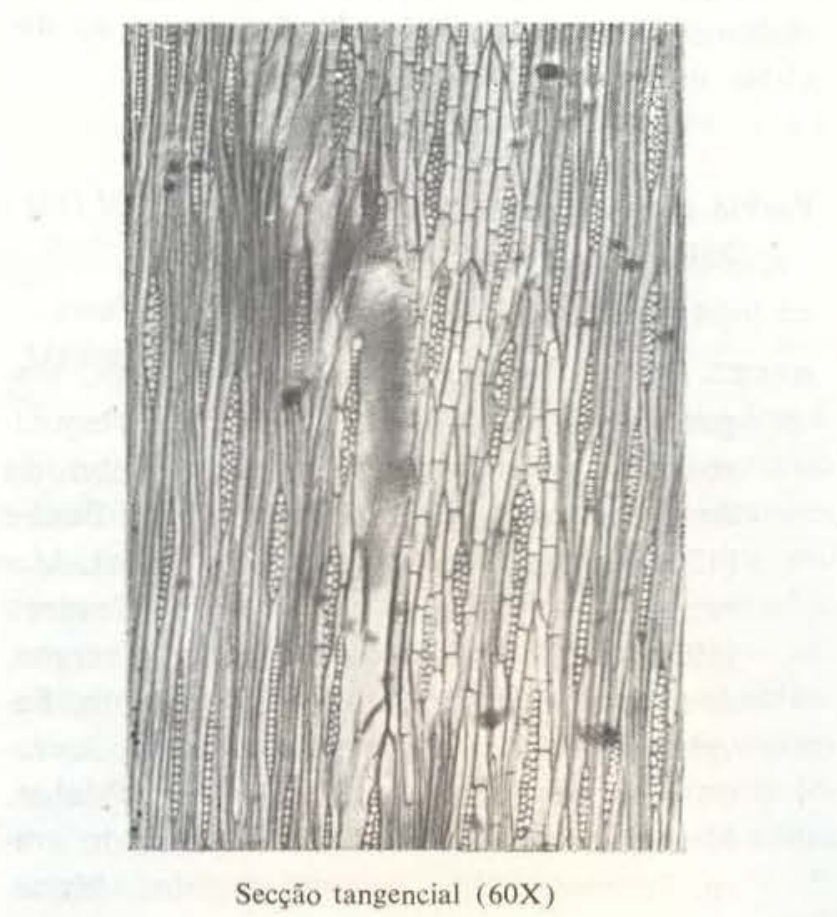


da de lente. Camadas de crescimento mal definidas. Máculas medulares e canais secretores não identificados.

\section{DESCRIÇÃO MICROSCÓPICA :}

Vasos de distribuição difusa, parede de espessura média, de secçăo ovalada a semi-circular; pequenos a grandes, diâmetro tangencial de $90-350$ micra, maioria entre $210-300$, micra $(72 \%)$, médios de $110-200(24 \%)$, even. tualmente pequenos e muito pequenos $(4 \%)$; de extremamente pouco a poucos de $1-5$, ocasionalmente até 7 vasos por $\mathrm{mm}^{2}$; solitários predominantes $(64 \%)$; múltiplos de $2-3$ $(33 \%)$, excepcionalmente de 4 vasos; pontuações intervasculares areoladas, guarnecidas, alternas, pequenas a médias $6-9$ micra, abertura inclusa; placas de perfuraçōes sim-ples; elementos vasculares são compostos de pequenos apêndices em uma ou em ambas extremidades, mais frequente em uma extremidade, de curto a longos, apresentando de 320 500 micra de comprimento, excepcionalments até 600 micra. Raios irregularmente distribuidos, homogêneos; uni e bisseriados $(85 \%)$, trisseriados, dificilmente até 4 células de largura; extremamente baixos, com uma variação de
100 - 400 micra de altura, com predominância os de $160-300$ micra $(76 \%)$, exporadicamente chegando a 440 micra de altura; muito numerosos $29-46$ raios por $\mathrm{mm}^{2}$, maioria entre 31 - $40(77 \%)$; altura em número de céiulas varia de $2-20$ células, verificando-se alguns raios com células envolventes; pontuaçoes radiovasculares ( $6-7$ micra) do mesmo tipo das incervasculares. Parênquima axial abundante, do tipo paratraqueal alitorme predominante, confluente, com presença de cristais rômbicos de oxalato de cálcio em suas célulés, seriado de 3 - 5 células, mais comuns os de 4 . ribras de paredes delgadas, de muito curtas a curtas de $900-1.500$ micra de comprimento, excepcionalmente até 1.700 micra, maioria entre $1.300-1.500$ de comprimento; lúmen grande (10 - 26 micra); espessura da parede $(4-6$ micra). Camadas de crescimento demarcadas por fibras de parede mais espêssa e de lúmen achatado. Máculas medulares e canais intercelulares não foram observados.

\section{usos comuns :}

Marcenaria, taboados, construção civil, caixotaria, móveis de pouco valor. O tronco da árvore serve para fabricação de remos, etc.

\section{QUADRO}

Resultados dos testes de Fava Bolacha (Parkia pendula Benth) visando à produção de celulose, segundo SUDAM - 1969.

\begin{tabular}{|c|c|c|c|c|c|c|c|c|c|c|c|c|}
\hline \multicolumn{6}{|c|}{ C O Z I M E N T O } & \multicolumn{4}{|c|}{$\begin{array}{c}\text { R E S I T E N C I A } \\
\text { A } 45^{\circ} \mathrm{SR}\end{array}$} & \multicolumn{2}{|c|}{$\begin{array}{l}\text { COMPRI- } \\
\text { MENTO DA } \\
\text { FIBRA }\end{array}$} & \multirow[t]{2}{*}{ OBS. } \\
\hline 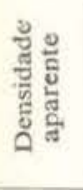 & 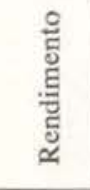 & 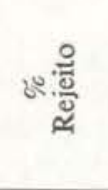 & 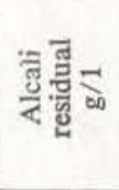 & 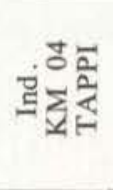 & 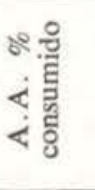 & 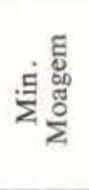 & 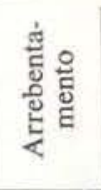 & 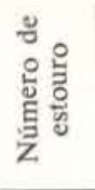 & 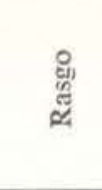 & 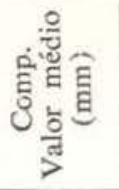 & 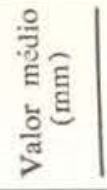 & \\
\hline 0.73 & 46.35 & 0,72 & 1,60 & 44,0 & 18,40 & 35 & 2.600 & 44,80 & 40,00 & 1,435 & 0,0208 & DURA \\
\hline
\end{tabular}

OBS. - A madeira é duro, requerendo assim mais Alcali ativo para seu cozimento normal, o número de permanganato é muito elevado. havendo portanto possibilidade de ser incluida no procésso em virtude das outras carocterísticas serem razoáveis. 
Parkia decussata Ducke in Arch. Jard. Bot. Rio de Janeiro, IV : 16 (1938)

BRASIL : Est. Amazonas - Faveira arara tucupi (Manaus)

Árvore grande, ocasional na mata da terra firme em solo argiloso; fuste cilíndrico, volumo. so e copa ampla. Folhas opostas, decussadas (4) 7 jugos; foliólulos glabros, oblongos, ápice- obtuso e base falciforme, inflorescências grandes em panículas terminais eretas, pouco ramificadas. Flores em capítulos longos, claviformes, ca. de $7 \mathrm{~cm}$ de comprimento, vermelho e estéril na parte inferior, e na superior fértil, brancoamarelada. Fruto legume lenhoso, indeiscente, ligeiramente recurvado e densamente recoberto por indumento vermelho-escuro; sementes eli. ticas, lisas, unisseriadas, 20 (25) por $12 \mathrm{~mm}$.

\section{Habitat :}

Matas primárias da terra firme, em solo argiloso.

\section{Ocorrência geográfica :}

Ducke (1949), afirma ser esta espécie largamente distribuída no Estado do Amazonas e ao redor de Manaus, alto rio Negro e no Solimões. No entanto, temos constatado ser pou- co frequente não só nos arredores da cidade como nas matas mais afastadas, chegando mes. mo a ter uma ocorrência muito ocasional nas matas da estrada BR-17 que liga Manaus ao vizinho município de Itacoatiara (INPA 21248), reconhecida ainda pelo mesmo autor, I.c. ao sul de Parintins, no Est. do Pará somente no limite oeste, e em juruti Velho.

\section{DADOS GERAIS SOBRE A MADEIRA}

\section{CARACTERÍSTICAS GERAIS :}

Madeira pesada $\left(0,75-0,80 \mathrm{~g} / \mathrm{cm}^{3}\right)$; cerne de côr avermelhado, alburno creme brilhante, quando seco, apresenta pequenas manchas de tonalidade acinzentadas; cheiro e gosto praticamente indistintos; textura fina: gră direita. Fácil de trabalhar, recebendo acabamento não muito atrativo. É uma espécie de menor possibilidade ao ataque de fungos e insetos do que a Parkia pendula.

\section{DESCRIÇÃO MACROSCÓPICA :}

Parênquima contrastado, apenas visível a olho nu, aliforme de aletas curtas, nitidas, excepcionalmente formando pequenos trechos tangenciais ou raramente confluente. Poros peque. nos a médios, pouco numerosos, visivel a olho

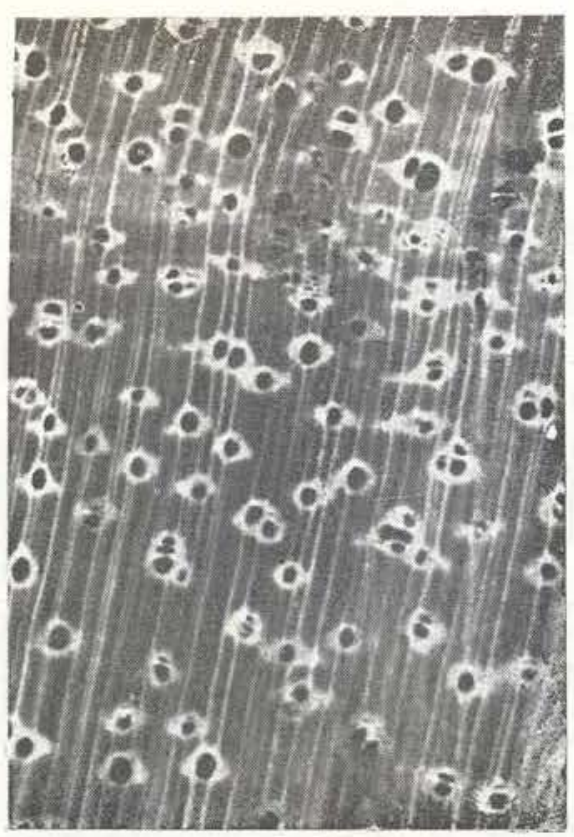

Secção transversal (10X)

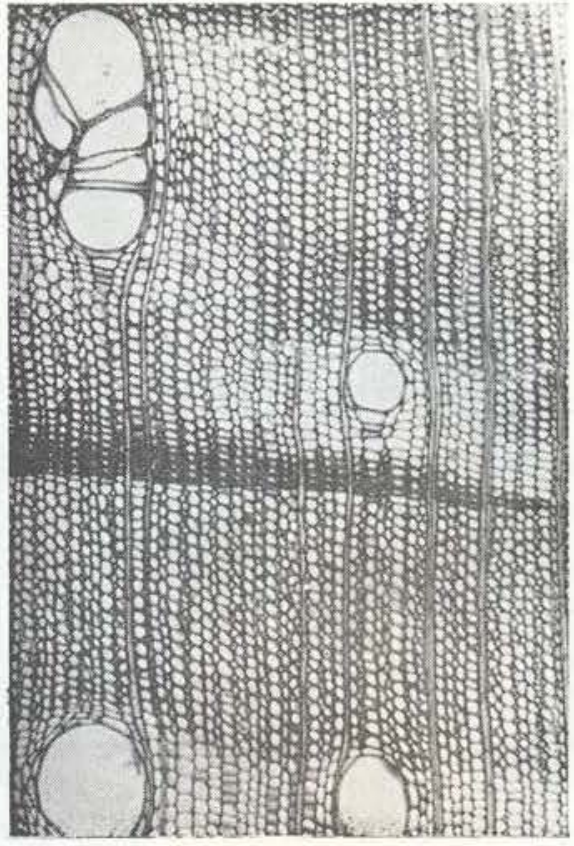

Secção transversal (60X) 
desarmado, solitários predominantes, múltiplos de $2-3$, notando-se alguns de 4 poros, vazios. Linhas vasculares são altas e retas. Raios no topo são finos e um tanto numerosos, apresentando boa uniformidade na largura e espaçamento, apenas notados sem ajuda de lente; no corte tangencial são dispostos irregularmente, no radial são contrastados. Camadas de crescimento pouco definidas, demarcadas por zonas fibrosas mais escuras. Máculas medulares $\epsilon$ canais secretores inaparentes.

\section{DESCRIÇÃO MICROSCÓPICA :}

Vasos distribuição irregular, parede de espessura média, forma quase circular ou ligeiramente ovalada; pequenos a médios, diâmetro tangencial variando de $90-200$ micra, eventualmente até 220 micra, maioria entre $130-170$ micra $(56 \%)$; de muito pouco a poucos de 2 6. raramente chegando até 7 vasos por $\mathrm{mm}^{2}$; solitários predominantes $(63 \%)$, múltiplos de 2 $(23 \%)$, pouco frequente os de $3-4$ vasos $(14 \%)$; pontuações intervasculares areoladas, pequenas ( 6 micra), alternas, guarnecidas, abertura inclusa, placas de perfurações simples; elementos vasculares de curtos a longos 300 600 micra de comprimento, ocasionalmente até 650 , compostos de apêndices de um lado ou de ambos. Raios dispostos irregularmente, homogêneos; bisseriados predominantes $(50 \%)$; os trisseriados $(30 \%)$; unisseriados $(18 \%)$; eventualmente tetrasseriados; extremamente baixos de 120 - 350 micra, maioria entre 160 - $300(70 \%)$, excepcionalmente até 380 micra de altura; muito numerosos de $23-37$ raios por $\mathrm{mm}^{2}$, predominando entre $26-35(82 \%)$; altura em número de células varia de $2-20$ células, eventualmente até $24-25$ células, notando-se que os unisseriados apresentam uma variação de $2-23$ células de altura, aparecendo com certa frequência células envolventes nos raios bisseriados e trisseriados; pontuações radiovasculares ( $4-6$ micra) do mesmo tipo das intervasculares. Parênquima axial abundante, aliforme predominante e vasicentrico. pouce confluente, paratraqueal, seriado de 2 6 células, com predominância de 4 , ocasionalmente até 7 . Fibras de curtas a longas, variando de $1.220-1.700$ micra de comprimento eventualmente chegando até 1.850 micra, maio-

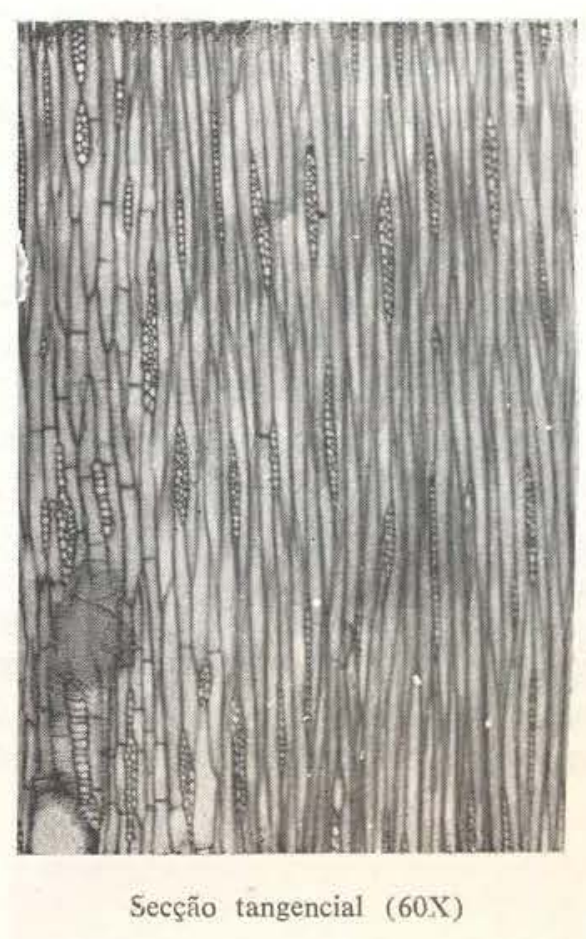

ria está entre $1.400-1.500$ micra de comprimento; parede fina, lúmen grande $(13-26 \mathrm{mi}-$ cra). Camadas de crescimento demarcadas por fibras de lúmen achatado. Máculas medulares e canais intercelulares não foram observados.

\section{USOS COMUNS :}

Caixotaria, taboados, marcenaria etc.

Parkia oppositifolia Bth., in Mart. FI. Bras. XV (III) : 267.

BRASIL: Est. Amazonas - Faveira benguê, F. pé arara, Benguê, Arara tucupi (Manaus); Visgueiro da terra firme (S. Paulo de Oliven. ça). Est. Pará - Paricá, Visgueiro (Belém); Japacanim (Óbidos, Porto de Moz), seg. Ducke (1925).

Árvore em geral de grande porte, copa larga, mais ou menos globosa, facilmente distinta das demais espécies do gênero pelo característico odor de salicilato de metila que exala a casca quando fresca. Folhas opcstas, peciolo com uma glandula ou esta não aparente, susten. tando 5 (8) pares de pinas multifolioluladas; foliólulos descíduos principalmente na época da floração (abril - maio) com indumento esbranquiçado na face inferior. Inflorescência termi- 
nal, curta $30(60) \mathrm{cm}$, com pedicelos opostos; flores em capítulos biglobosos na parte inferior com estaminódios brancos e longos, de diâmetro maior do que na parte superior, amarelado. fértil, com estames curtos, exsertos. Fruto legume de 20 (25) $\mathrm{cm}$ de comprimento, piloso quando jovem, mais tarde glatro, arroxeado, longo estipitado na base; estipite ligeiramente recurvado; sementes oblongas, convexas lateralmente, arilo delgado mais ou menos solto.

Habitat: Freqüente na mata primária ou secundária da Amazônia, particularmente em terreno firme, argiloso.

Ocorrência geográfica: Amazônia, Território Federal de Rondônia, regicâo sul da Guiana Inglesa e Peru amazônico Ducke (1949).

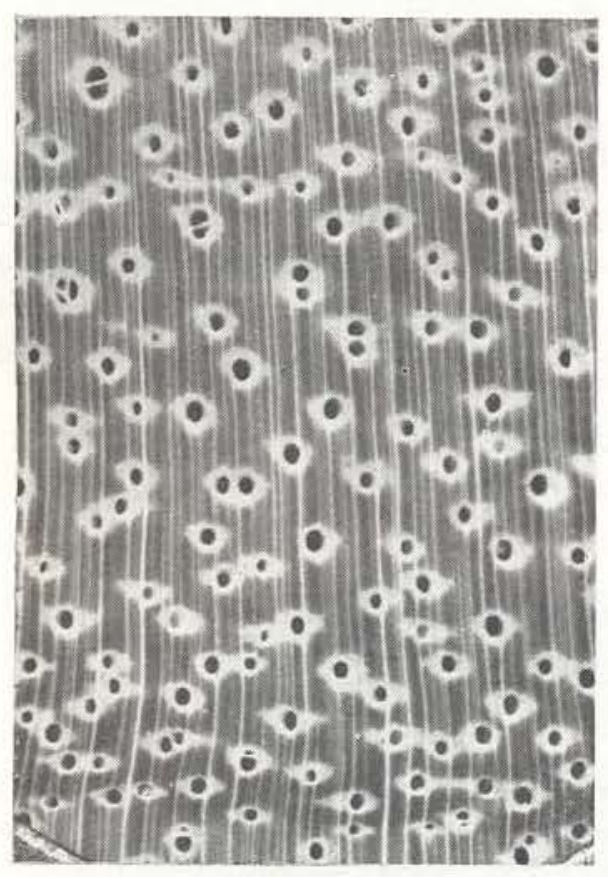

Secção transversal (10X)

DADOS GERAIS SOBRE A MADEIRA

\{Seg. Loureiro e Silva, 1968!

CARACTERÍSTICAS GERAIS :

Madeira leve $\left(0,40-0,55 \mathrm{~g} / \mathrm{cm}^{3}\right)$; de cor bege levemente rosada, uniforme, grã regular para irregular, textura média para grosseira gôsto e cheiro indistintos; superfície de brilho pouco acentuado. Fácil de trabalhar, tomando bom acabamento.

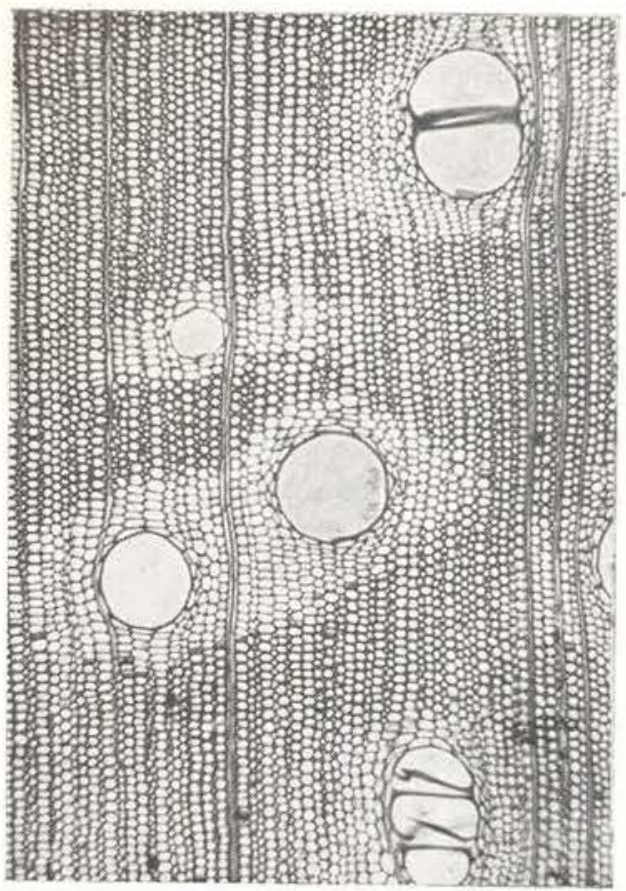

Secção transversal $(60 X)$

\section{DESCRIÇÃO MACROSCÓPICA :}

Parênquima apenas distinto a olho nu, vasicêntrico, pouco confluente e aliforme predominante de aletas curtas, às vezes ligando os poros. Poros perceptíveis a simples vista, paucos, pequenos a médios, solitários, geminados e algumas cadeias radiais, geralmente vazios. Linhas vasculares são longas e retas, distintas a olho desarmado. Raios no topo observados somente com ajuda de lupa, irregularmente dispostos; na face tangencial são curtos e de distribuição irregular, na radial são contrastados. Camadas de crescimento demarcadas por zonas fibrosas escuras. Canais secretores e Máculas medulares não observados.

\section{DESCRIÇÃO MICROSCÓPICA :}

(Seg. Mainieri, 1962)

Vasos distribuição difusa, forma quase circular ou ligeiramente ovalada, angulosa muito pouco acentuado; parede delgada; muito poucos $2-5(90 \%)$, raramente de $8-9$ por $\mathrm{mm}^{2}$; raros campos sem presença de poros; médios em maioria e grandes, geralmente entre $140-220$ micra, raramente até 260 micra de diâmetro tangencial; solitários $(70 \%)$ e múltiplos de 


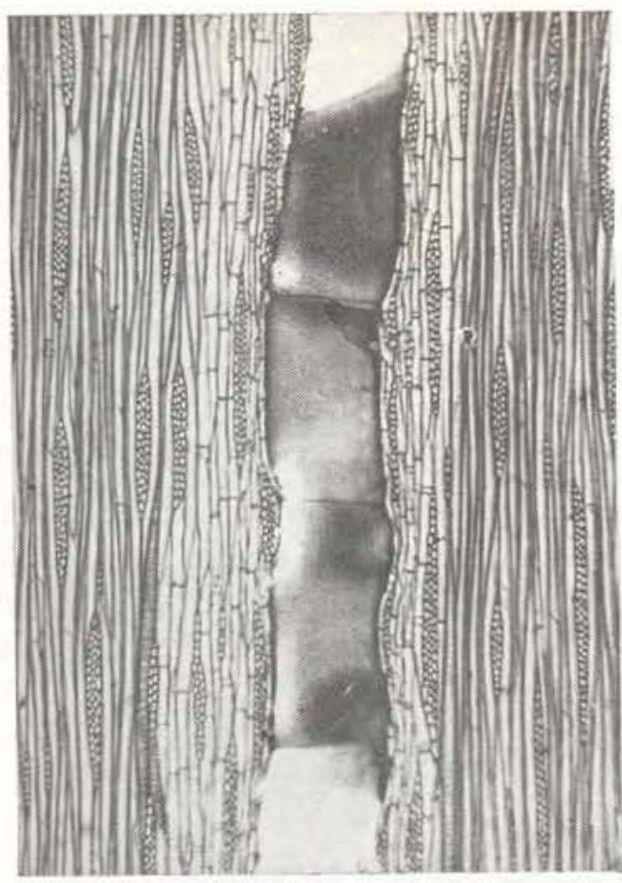

Srcção tangencial $(60 \mathrm{X})$

2 - 3; pontuações intervasculares pequenas (6 - 7 micra), alternas, poligonais, guarnecidas, abertura inclusa; placas de perfurações simples; elementos vasculares de $300-680$ $(100 \%)$ micra de comprimento. Raios dispos. tos irregularmente; homogêneos de células pro- cumbentes; multisseriados, predominando os de $2-3$ células de largura, raros os de 4 , sendo, porém, os de 2 células localmente bisseriados, e os múltiplos (3-4), na maioria das vezes, são de $2-6$ células marginais procumbentes: unisseriados, relativamente abundante, de células procumbentes; extremamente baixos, geralmente entre $250-500$ micra de altura, excepcionalmente até 600 micra; pouco numerosos $4-7(80 \%)$, com variação de $2-8$ raios por milimetro; pontuações radiovasculares pequenas e do tipo das intervasculares. Parênquima axial abundante, aliforme predominante, e vasicêntrico, pouco confluente. Fibras de parede fina e lúmen grande ( $13-20$ micra) de secção quase circular, em séries radiais. pouco regulares; pontuações simples; elementos fibrosos vai de $990-1.460(100 \%)$ micra de comprimento. Camadas de crescimento demarcadas por fibras de parede mais espêssa e lúmen achatado.

USOS COMUNS :

Caixotaria, construção em geral, podendo ser utilizada na fabricação de papel; rendimento em celulose $46,0 \%$ - comprimento das fibras 1,40 - diâmetro 0,020 (A. Bastos M.C.P.), in Le Cointe (1947).

QUADRO

Resultado de análise química de Visgueiro (Parkia oppositifolia), segundo Melo $\in t$ al. (1971)

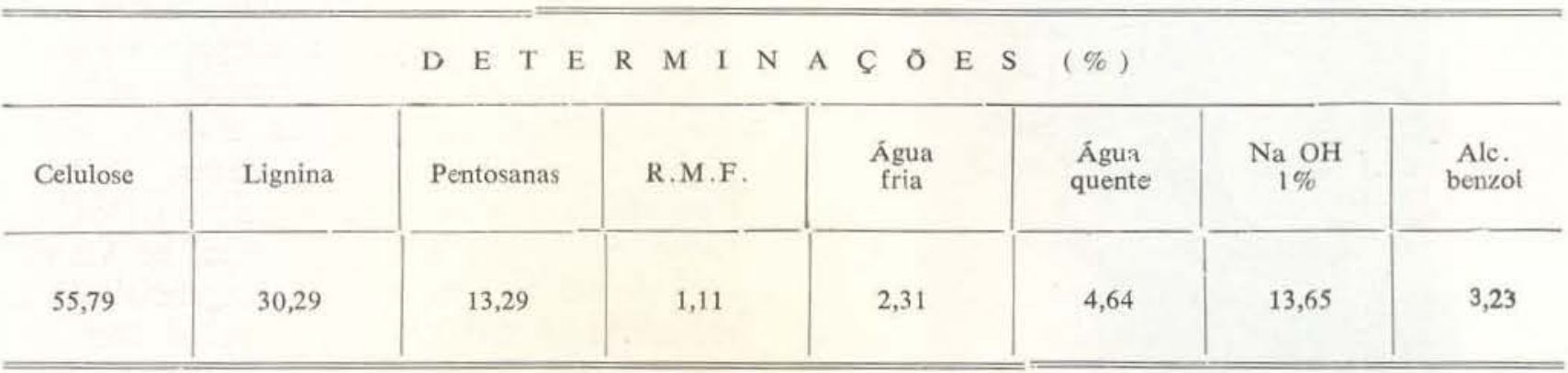

Parkia gigantecarpa Ducke, in Arch. Jard. Bot. Rio de Janeiro, I (1):19 (1915)

BRASIL: Est. Amazonas - Japacanim (médio rio Negro), cf. Ducke (1949). Est. Pará Visgueiro (Belém), ibid.

Árvore de dimensōes enormes, possivelmente a maior do gênero em todos os aspectos.
A copa, lembra à distância a $P$. pendula com enormes vagens pendentes ou ainda com os capítulos floriferos igualmente fétidos como naquela espécie, sustentados por longos e filiformes pendúnculos.

As folhas, maiores do que em qualquer outra espécie do gênero, são opostas, e a face 
inferior dos foliólulos é recoberta por um indumento branco ou acinzentado como em $P$. oppcsitifolia, diferindo desta nas dimensões, que no caso, são maiores. Também, a casca da árvore em estado fresco, não apresenta o característico odor de salicilato de metila existente nesta última.

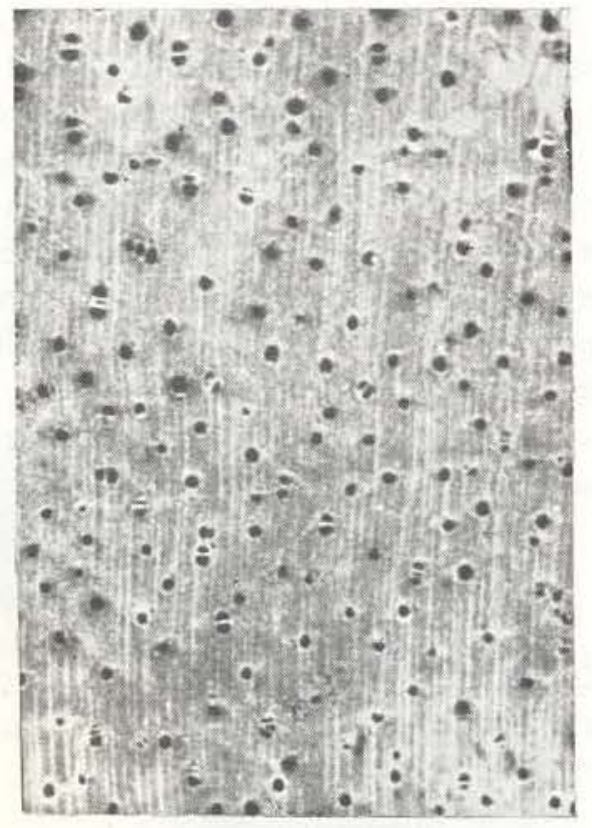

Secção transversal $(8 \mathrm{X})$

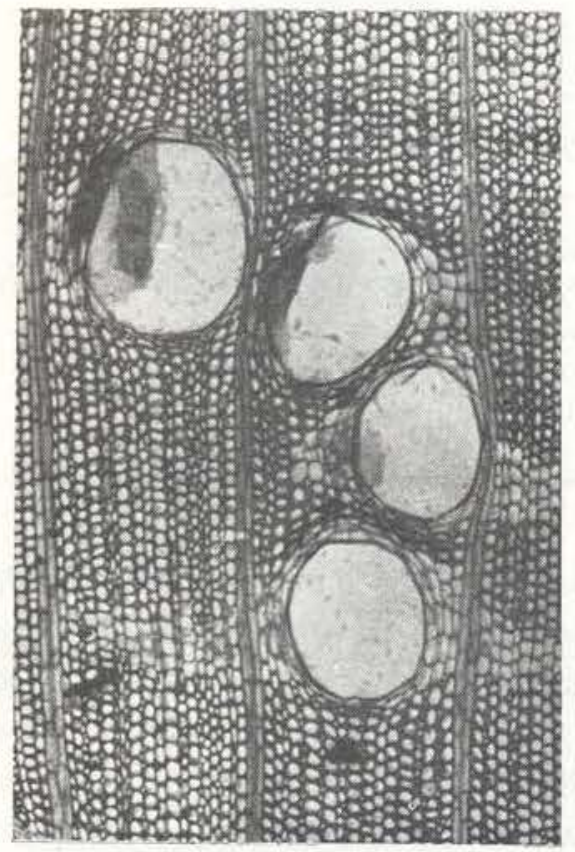

Secção transversal (60X)
Inflorescência biglobosa, capítulos brancos, volumosos, $10(23) \mathrm{cm}$, com estaminódios amarelos constituídos de 3 partes - uma basal estéril, uma mediana curta em relação as demais, e uma terceira apical fértil. Fruto legume longo, 50 (90) $\mathrm{cm}$ de comprimento por 5 (6) de largura, ligeiramente recurvado e es tipitado na base.

Habitat: Ocorre nas matas primárias e securi dárias da terra firme, em solo arenoso.

Ocorrência geográfica: No Est. do Amazonas seg. Ducke, I.c., ocorre em Maués e médio rio Negro. No Pará, parece ser freqüente em todo o Estado. Reconhecida ainda nos Ter. Fed de Rondónia e Amapá (Serra do Navio-INPA, 10287), ao sul da Cuiana Inglesa e Peru amazônico.

\section{DADOS GERAIS SOBRE A MADEIRA}

\section{CARACTERÍSTICAS GERAIS :}

Madeira pesada $\left(0,70-0,75 \mathrm{~g} / \mathrm{cm}^{3}\right)$; cerne de cor avermelhado, alburno creme brilhante, com grande predominância de manchas acinzentadas, bem características; insipida e inodora; textura fina; grã direita. Boa de trabalhar, podendo receber acabamento não atrativo.

\section{DESCRIÇÃO MACROSCÓPICA :}

Parênquima contrastado, visive! sob lente, aliforme predominante de aletas curtas, vasicêntrico. Poros visiveis a simples vista, pequenos a médios; pouco numerosos; solitários predominantes, múltiplos de $2-3$, vazios Linhas vasculares são altas, retas. Raios no topo são finos e numerosos, interrompidos, uniforme na largura e espaçamento, só visíveis com auxílio de lupa; na face tangencial são irregularmente distribuidos; na radial bem visiveis a olho nu. Camadas de crescimento às vezes demarcadas por zonas mais escuras. Máculas medulares presentes. Canais secretores ausentes.

DESCRIÇÃo MICROSCÓPICA :

Vasos de forma quase circular ou ligeiramente ovalada, espessura da parede, média; pequenos a grandes, diâmetro tangencial vari- 


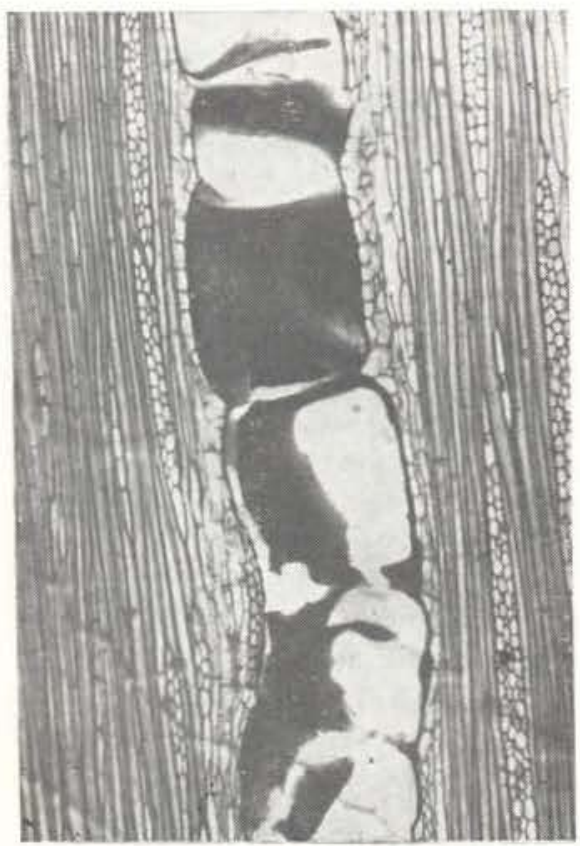

Secção tangencial (60X)

ando de $100-310$ micra, maioria entre $160-300$ micra $(92 \%)$ eventualmente encontra-se de $80-320$ micra de diâmetro, de extremamente poucos a muito poucos, chegando até 4 , às vezes 5 por $\mathrm{mm}^{2}$, havendo campo com um único vaso ou excepcionalmente campo sem presença de vasos; predominantemente solitários $(80 \%)$, múltiplos de $2-3(20 \%)$; pontuações intervasculares areoladas, alternas guarnecidas, pequenas $(5-6$ micra $)$, abertura inclusa; placas de perfurações simples; ele mentos vasculares de curtos a longos, variande de $350-520$ micra de comprimento, composto de pequenos apêndices. Raios de distribui. ção irregular, heterogêneos tipo II $-\mathrm{A}$; de uni a tetrasseriados, predominando os de uni e trisseriados $(72 \%)$, bisseriados $(13 \%)$, tetrasseriados $(15 \%)$; de extremamente baixos a baixos de $150-1.850$ micra de altura; de numerosos a muito numerosos $9-20$ por $\mathrm{mm}^{2}$, com predomi. nância os de $11-15(52 \%)$; altura em núme. ro de célula variando de $1-53$, excepcional. mente até $55-58$, predominando de $1-40$ células $(76 \%)$; pontuações radiovasculares $(6-10$ micra) iguais as intervasculares. .Parênquima axial relativamente abundante, aliforme predominante e vasicentrico, pouco confluente , paratraqueal. Fibras de curtas a longas indo de $1.100-1.800$ micra de comprimento. ocasionalmente até 1.850 micra ,maioria entre $1.600-1.800(66 \%)$; parede fina, lúmen grande variando de $10-20$ micra. Camadas de crescimento bem demarcadas por zonas $\mathrm{f}$ brosas de lúmen quase achatado. Máculas medulares pouco presente. Canais intercelulares não observados.

\section{USOS COMUNS :}

Caixas, marcenaria, taboados, etc.

Parkia multijuga Bth. in Mart. FI. Bras. XV (IIi) : 265.

\section{$=$ Dimorphandra megacarpa Rolte}

BRASIL : Est. Amazonas - Faveira.

Est. Pará - Paricá grande da terra firme.

Árvore amazônica de grandes dimensões, com folhas alternas, $12(20) \mathrm{cm}$ de comprimento, multipinadas, distinta das demais espécies do gênero pelos característicos frutos recurvados, curtos e largos, e pelos foliólulos geralmente recobertos por indumento esbranquiça. do na face superior. Inflorescência em paniculas terminais pouco ramificadas, relativamente curtas, com flores amarelo-brancacentas em capítulos globosos de $3(5) \mathrm{cm}$ de diâmetro -

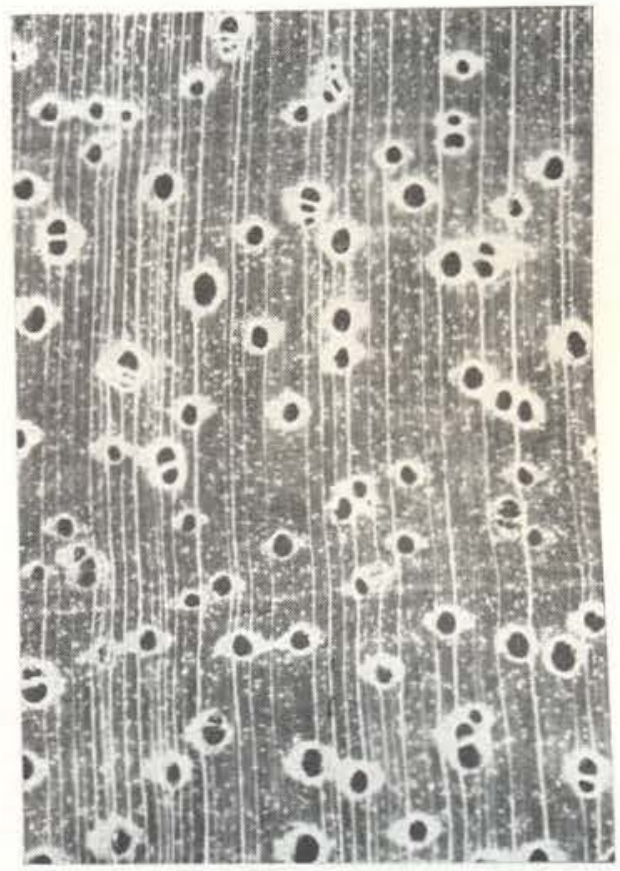

Secção transversal (10X) 
as masculinas na base, e as hermafroditas na região central. Fruto legume glabro, fortemente lenhoso, indeiscente, aplanado, recurvado, de $20(29) \mathrm{cm}$ de comprimento, por $7(9) \mathrm{cm}$ de lar. gura, uniforme da base ao ápice, com $2,5(3) \mathrm{cm}$ de espessura; sementes alongadas, unisseriadas no fruto.

Habitat: Ocorre com freqüência na mata primária ou secundária em solo particularmente argiloso, e seg. Ducke (1949), tam. bém na várzea alta de toda a região Amazônica.

Ocorrência geográfica: Amazônia, Território de Roraima, Peru e Colômbia.

\section{DADOS GERAIS SOBRE A MADEIRA}

(Seg. Loureiro \& Silva, 1968)

\section{CARACTERÍSTICAS GERAIS :}

Madeira leve $\left(0,50-0,55 \mathrm{~g} / \mathrm{cm}^{3}\right) ;$ cerne creme com listras róseas pouco diferenciado do alburno esbranquiçado; ligeiramente lustrosa e pouco áspera ao tato; textura média, sem gostc ou cheiro pronunciado. Fácil de trabalhar; toma bom acabamento.

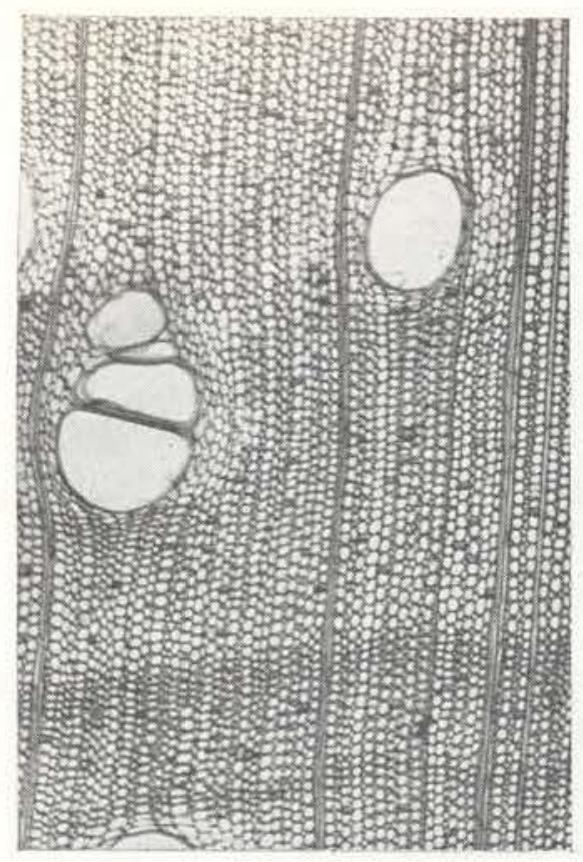

Secção transversal (60X)

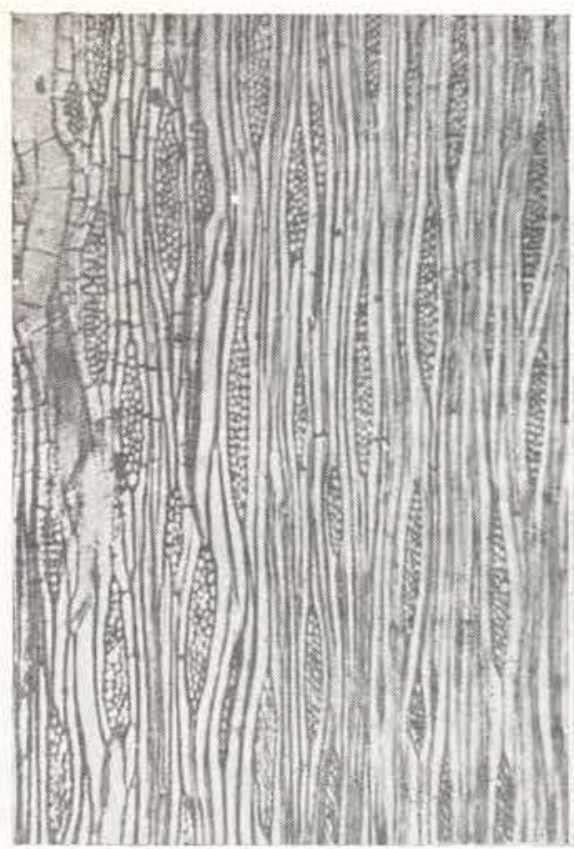

Secção tangencial (60) DESCRIÇÃO MACROSCÓPICA :

Parênquima pouco contrastado, relativamente abundante, apenas visível a olho nu, distinto com ajuda de lente, aliforme de aletas curtas, algumas mais longas, às vezes ligando alguns poros, vasicêntrico. Pores visíveis a simples vista. poucos, pequenos a médios, alguns grandes, solitários, geminados e outros agrupados em pequenas cadeias radiais, vazios e alguns contendo resina oleosa. Linhas vasculares distintas sob lente, longas e retas, vazias. Raios no topo bem distintos sob lente, finos, um tanto numerosos; na face tangencial são curtos e irregularmente distribuidos; na radial são contrastados. Camadas de crescimento demarcadas aparentemente por finissimas linhas do parênquima terminal. Máculas medulares e Canais secretores não identificados.

DESCRIÇÃO MICROSCÓPICA :

Vasos distribuição difusa, de forma quase circular ou ligeiramente ovalada, parede angulosa, pouco acentuado; parede delgada; muito pouco $(90 \%)$, raramente 8 por $\mathrm{mm}^{2}$; alguns campos com um único vaso, ou excepcionalmente campo sem vasos; médios e grandes, 
maioria entre $170-230$ micra de diâmetro tangencial; pontuaçōes intervasculares alternas, poligonais, pequenas $(8-10)$ micra, guarnecidas e de abertura inclusa; placas de perfurações simples; elementos vasculares de $500-750(75 \%)$ e de $400-500(20 \%)$, comprimento máximo 770 micra. Raios dispostos irregularmente, multisseriados de $3-4$, e de 5 células de largura, homogêneos de células procumbentes, poucos raios unisseriados de células procumbentes; extremamente baixos $(95 \%)$, maioria entre $170-430$ micra, raramente até 520 micra de altura; pouco numerosos $(4-7)$, raramente até 10 raios por milímetro; pontuações radiovasculares do mesmo tipo das intervasculares; óleo resina comum nas paredes celulares. Parênquima axial abundante, para . traqueal aliforme e vasicêntrico, pouco confluente; difuso, cohstituído de células esparsas; cristais abundantes, em séries longas. Fibras parede de espessura média e de lúmen distinto, (9 - 16) micra; pontuações simples; elementos fibrosos de $1.000-1.500(80 \%)$ e de $770-1.000(15 \%)$, comprimento máximo 1.700 micra. Camadas de crescimento distintas, demarcadas por fibras de lúmen achatado $e$ de parede espêssa.

\section{USOS COMUNS :}

Caixotaria, construção de interior.

QUADRO

Resultados de algumas propriedades físicas da madeira de Faveira arara tucupi (Parkia multijuga Benth), segundo SUDAM - 1969.

\begin{tabular}{|c|c|c|c|c|c|c|c|c|}
\hline \multirow{3}{*}{$\begin{array}{l}\text { Umidade } \\
\text { inicial }\end{array}$} & \multirow{3}{*}{$\begin{array}{l}\text { Tempo de } \\
\text { secagem } \\
\text { até } 20 \%\end{array}$} & \multirow{3}{*}{$\begin{array}{l}\text { Mínimo de } \\
\text { secagem }\end{array}$} & \multirow{3}{*}{$\begin{array}{c}\% \\
\text { umidade }\end{array}$} & \multirow{3}{*}{$\begin{array}{c}\text { Mês de } \\
\text { mediçẫo } \\
\text { da umidade }\end{array}$} & \multicolumn{4}{|c|}{ CONTRACÃO } \\
\hline & & & & & \multicolumn{2}{|c|}{ Radial } & \multicolumn{2}{|c|}{ Tangencial } \\
\hline & & & & & $\begin{array}{l}\text { P. S. } \\
\text { ao ar }\end{array}$ & $\begin{array}{l}\text { P. S. } \\
\text { ao forno }\end{array}$ & $\begin{array}{l}\text { P. S. } \\
\text { ao ar }\end{array}$ & $\begin{array}{l}\text { P. S. } \\
\text { ao forno }\end{array}$ \\
\hline $71,1 \%$ & 20 dias & 44 dias & $14,2 \%$ & 4 & 1,2 & 2,2 & 1,6 & 4,5 \\
\hline
\end{tabular}

\section{AgRADECIMENTOS}

Registramos nossos agradecimentos a Ozorio José de M. Fonsêca, Diretor da 2. Divisão do INPA, pelas microfotografias que ilustram êste trabalho.

\section{SUMMARY}

In this paper a contribution to the dendrological knowledge of the amazonian species of the genus Parkia (Leguminosae) in given by the authors, by including the botanical description, geographical distribution, habitat and anatomical description of the woods of the following species: $\mathbf{P}$. pendula, $\mathbf{P}$. decussata, $\mathbf{P}$. oppositifolia, $\mathbf{P}$. gigantocarpa and $\mathbf{P}$. multijuga. A table showing the main differential structures of their woods is also presented, including 15 photos.

\section{BIBLIOGRAFIA CITADA}

BENA, P.

1960 - Essences forestières de Guyane. Paris, Bureau Agricole et Forestier Guayanais, Imprimerie Nationele. p.: 101.

BRAGA, $R$.

1960 - Plantas do Nordeste, especialmente do Ceará. 2. ed. Fortaleza, Imp. Oficial. p.: 478-479.

Brasil. SUPERINTENDÊNCIA DO DESENVOLVIMENTO DA AMAZÔNIA

1969a- Algumas informaşōes úteis sôbre madeiras da Amazônia. Relotório sôbre a possibilidade de 50 madeiras da Amazônia. Belém, 49 p.

$1969 \mathrm{~b}$ - Ensaios sistemáticos no campo da tecnologia de madoiras da Amazônia. Algumas propriedades físicas de 50 madeiras amazônicas. Belém. 5 p.

$1969 \mathrm{c}$ - Possibilidades de utilização econômica das madeiras da regiāo Amazônica para produção de celulose. p.: 6,10 . 
1969d-Algumas informações úteis sôbre madeiras da Amazônia. Resultados de testes efetuados com madeiras da Amazônia. Belém, 6 p.

Chattaway, M. M.

1932 - Proposed Standards for numerical vaiues used in discribing woods. Trop. Woods, New Ha. ven, 29.: 20-28.

DUCKE, A.

1925 - As Leguminosas do Estado do Pará. Archos. Jard. Bot., Rio de Janeiro, $4:$ 256-7.

1938 - Plantas nouvelles ou peu connues de la région amazonienne. (Va. série). Archos. Jard. Bot., Rio de Janeiro, 6.: 16.

1949 - As Leguminosas da Amazônia Brasileira. Notas sôbre a flora neotrópica. II. Bolm. Téc. Inst. Agron. Norte, Belém, 18: 65-68.

FróES, R. L.

1959 - Informações sôbre algumas plantas econômicas do Planalto Amazônico. Bolm. Téc. Inst. Agron Norte, Belém, 35:47

LE COINTE, $P$.

1947 - Amazônia Brasileira. III - Arvores e plantas úteis (Indigenas e aclimadas). 2. ed. São Pau1o, Ed. Nacional. (Brasiliana, série 5a, v. 251). p. $235,493-494$.

Lindeman, J. C. \& Mennega, A. W.

1963 - Bomemboek voor Suriname. Mededelingen van het Botanisch Museum en Herbarium van de Rijksuniversiteit te Utrecht, 200.: 187.

Loureiro, A. A. \& Silva, M. F. DA

1968 - Catálogo das madeiras da Amazônia. Belém, SUDAM, 2 v. p.: 23-28.

MAINIERI, C.

1962 - Madeiras leves da Amazônia empregadas em caixotaria. Estudo anatômico macro e microscópico. Publ. Inst. Pesq.. Tec., São Paulo, $686: 15-17$.

MELo, C. F. M. DE ET ALII

1971 - Madeiras tropicais para reflorestamento, celulose e papel. Inst. Pesq. Exp. Agrop, do Norte; série: Tecnológica, Belém, 2(1).: 20.

MENEZES, A. I.

1949 - Flora da Bahia. Descrição das espécies nativas e aclimadas na Bahia e em todo o Brasil, com as identificações científicas, suas características $e$ utilidades. São Paulo, Ed. Nacional. (Brasiliana, série.: $5^{\text {a }}$ v. 246), p.: 43.

Milanez, F. Romano \& Bastos, A. de Miranda

1960 - Glossário dos têrmos técnicos usados em anatomia da madeiras. Anu. Bras. Econ. Flor. Rio de Jantiro, 12(12) : 1-27.

TAVARES, $\mathrm{S}$.

1959 - Madeiras do Nordeste do Brasil. Monografia da Univ. Rural de Pernambuco, 5.: 43-44. 
PRINCIPAIS CARACTERES ANATOOMICOS DIFERENCIAIS DO LENHO DAS ESPÉCIES ESTUDADAS

\begin{tabular}{|c|c|c|c|c|c|}
\hline ELEMENTOS & P. pendula & P. decussata & P. oppositifolia & P. gigantocarpa & P. multijuga \\
\hline Peso específico $(*)$ & $0,80-0,85$ & $0,75-0,80$ & $0,40-0,55$ & $0,70-0,75$ & $0,50 \cdot 0,55$ \\
\hline \multicolumn{6}{|l|}{ Vasos: } \\
\hline Diâmetro (micra) & $90-350$ & $90-220$ & $100-260$ & $80-320$ & $120-280$ \\
\hline Número por $\mathrm{mm}^{2}$ & $1-7$ & $2 \cdot 6$ & $0-7$ & $0 \cdot 5$ & $0-6$ \\
\hline $\begin{array}{l}\text { Elementos vasculares } \\
\text { (micra) }\end{array}$ & $320-600$ & $300-600$ & $300-680$ & $350-520$ & $400-770$ \\
\hline \multicolumn{6}{|l|}{ Raios : } \\
\hline Tipo & Homogêneo & Homogêneo & Homogêneo & $\begin{array}{c}\text { Hetercrêne: } \\
\text { II-A }\end{array}$ & Homogêneo \\
\hline Altura em micra & $100 \cdot 440$ & $120-380$ & $250-600$ & $150-1.850$ & $170-520$ \\
\hline Altura número de células & . $2 \cdot 20$ & . $2-25$ & 一 & $1-58$ & - \\
\hline Largura em células & $1 \cdot 4$ & $1 \cdot 4$ & $1 \cdot 4$ & $1-4$ & $1 \cdot 5$ \\
\hline Número por $\mathrm{mm}^{2}$ & $29-46$ & $23-37$ & $2-8$ & $9-21$ & $4-10$ \\
\hline Células envolventes & Presentes & Presentes & Ausentes & Ausentes & Ausentes \\
\hline \multicolumn{6}{|l|}{ Pontuaçōes: } \\
\hline Intervasculares (micra) & $6-9$ & 6 & $6-7$ & $5-6$ & $8-10$ \\
\hline Radiovasculares (micra) & $6-7$ & $4 \cdot 6$ & 一 & $6-10$ & - \\
\hline \multicolumn{6}{|l|}{ Fibras: } \\
\hline Comprimento (micra) & $900-1.700$ & $1.220-1.850$ & $990-1.460$ & $1.100-1.850$ & $770-1.750$ \\
\hline Lúmen & $10-26$ & $13-26$ & $13-20$ & $10-20$ & $9 \cdot 16$ \\
\hline Espessura da parede & $6 \cdot 8$ & $3.3-6.6$ & $3.3-4$ & $3.3-6.6$ & $3.3 \cdot 4$ \\
\hline Cristađs & Abundantes & Não observados & Nâo observados & Năo observados & Abundantes \\
\hline
\end{tabular}

(*) - Madeira seca ao or $(\mathrm{g} / \mathrm{cm} 3)$. 